\title{
Disability, Queer Phenomenology, and the Politics of Personhood
}

\author{
Thomas Abrams \\ University of Toronto
}

This paper explores Sara Ahmed's Queer Phenomenology from a disability studies perspective. In addition to her emphasis on race and desire, I ask how we might use Ahmed's queer, cultural phenomenology to ask about the sociomaterial basis of disablement, reflecting on the interactive emergence of these subjectivities more generally. In the first section of this paper, I examine the three main chapters in Ahmed's important book. I then ask what Ahmed might have asked, if she had explored disability therein. Next, I turn to some phenomenological disability studies, interrogating how subjectivity is put to work in the shared world, rather than universally accorded to all persons at all times. In the final section of this paper, I return to the basis of the phenomenological project itself, and ask what this revised version of subjectivity means for the phenomenology of Heidegger and Husserl, with an eye to future work.

Key words: Phenomenology; Disability; Queer Theory; Racialization; Sara Ahmed

Sara Ahmed's Queer Phenomenology has little to say about disabled personhood. To point this out is hardly a biting critique: most phenomenological work in disability studies has had little to say about race or sexual orientation. On these topics Ahmed says quite a bit. This paper, then, dwells on a single, very simple question: how might we do these projects at once, using her work as inspiration? To do so, I first outline the major arguments found in Ahmed's important book. In section two, I introduce the reader to some recent work in the phenomenology of disability. Though the terminology differs, we are on shared ground. Both projects locate the politics of personhood_racialized, disabled, queer or otherwise - in the interaction order. Following Ahmed, I explore "interaction" at two different yet interrelated registers, the individual and the institutional. In the third section of this paper, I return to phenomenological philosophy as a method for interrogating meaningful human existence in all its forms. There I argue that "subjectivity" is an emergent product of a material and symbolic order, not an inherent property of conscious existence. I substantiate this claim with disabled and queer phenomenology interrogated above, tempered with the classic phenomenological work of Heidegger and Husserl. I end by thinking about some other places where we might put this synthesis to work, both philosophically and, more importantly, in our everyday lives. 


\section{Queer Phenomenology}

Queer Phenomenology has three substantive chapters. My outline and annotation shall follow suit, at a paragraph apiece. Ahmed turns to objects in chapter one, where she makes use of existing phenomenological work on our existence with things (Heidegger, Being and Time; Leder), coupled with Marx's theory of commodity fetishism, to examine how oriented action is materially equipped. She looks especially to Husserl's desk, as explored in his Ideas. Not only does she ask what phenomenology tells us about objects and our orientations to them, but also the material requirements that are necessary for us to perform phenomenology in the first place. What work, what gendered work, must take place for us to perform the phenomenological epoché? "To what extent does philosophy depend on the concealment of domestic labor and of the labor time that it takes to reproduce the very materials of home?" (31) The philosophical outlook, then, is a mode of orientation that can only exist on a gendered base. Indeed, all forms of orientation intertwine in, through, and around materiality-"objects and bodies work together as spaces for action" (51). Queering phenomenology demands that we take "the material" seriously, as the basis of any philosophical exploration of personhood.

In chapter two, "Sexual Orientation" (pp. 65-108), Ahmed touches on matters of embodied difference, and pursues a phenomenology of sexual desire. She rereads Freud's psychoanalysis of homosexual behaviour as a "straightening device," an object, space, or mentality that reproduces compulsory heterosexuality as preferable. Freud's psychoanalysis is but one instance of many such devices, where deviant bodies are made problematic. She extends the critique of a compulsory orientation to that of sexual orientation as a natural status possessed by subjects.

The fantasy of a natural orientation is an orientation device that organizes worlds around the form of the heterosexual couple, as if it were from this "point" that the world unfolds. . . . The very idea that bodies "have" a natural orientation is exposed as fantasy in the necessity of the enforcement of that orientation, or its maintenance as a social requirement for intelligible subjectivity (85).

Two points are especially important here. On the one hand, compulsory heterosexuality, as a cultural form maintained through spaces, objects and their relations (in this case, the early psychoanalytic assemblage) is another trajectory through which we can interrogate ableism and 
normalcy, key concerns in disability studies. We are examining "compulsory ability" through the same phenomenological lens as compulsory heterosexuality (McRuer). Secondly, I want to press Ahmed on matters of subjectivity (and will continue below). It is not only the intelligibility of subjectivity that is at issue: it is subjectivity itself. If we must pursue a particular line in order to be subjects, then pre-existing and pre-shaped subjectivity itself must be called into question.

Chapter three, "The Orient and Other Others" (pp. 110-156) applies Ahmed's hermeneutic approach to race and racialization, space and spatialization. Building on the materially equipped phenomenology of orientations, pursued above, she asks how the phenomenological "I-can" is institutionalized in orientalism, whiteness, and her personal biography. "Phenomenology helps us to show how race is an effect of racialization, and to investigate how the invention of race as if it were 'in' bodies shapes what bodies 'can do'" (112). She does so by re-framing space from mere measurement to phenomenal space, what Heidegger (Being and Time) calls "availability". Reading the orientalism literature through her queered phenomenological lens, the Orient becomes "a matter of how bodies inhabit spaces through shared orientations" (p. 118). This she extends to whiteness. Whiteness is not a property found in bodies. It is found in availability, how they cohere in material cultures, institutional lines that admit some bodies and not others. They are defined in terms of the institutionalized "ability-to-". In family histories, race is a straight line accorded to some "pure" bodies, Others "mixed". Whiteness also manifests in habit spaces, where some bodies are permitted to exist, pass, and dwell as normal, Others marked, inhibited, made out of place. In each case, the ability-to (or its opposite) is not simply an attribute bodies have; it is aligned, accorded and denied in the life-world.

As I wrote in the introduction to this paper, Ahmed's book does not address disability. This should not obscure her accomplishments. What her book does do is give phenomenological theory and method a series of tools through which to address orientations, of all sorts, in ways anew. She draws novel insights from classic texts, breathing new life into the (frequently dry an often repetitive) phenomenological canon. This already makes the book valuable. Queer Phenomenology also has some important lessons for phenomenological disability studies, and, as I will argue below, vice versa. In pursuing this dialogue, we return to the basis of the phenomenological project itself. Her book is not simply a phenomenology of queer identity; it queers the phenomenological project writ large, asking about the selective account that phenomenology takes as emblematic of "the 
human", a much needed attempt to break the philosophy free of its historical rigidity. It is a phenomenology curious about its own founding orientations. People doing phenomenological disability studies-and phenomenology of every other sort-would do well to pay attention. We should pay attention not only to race, sexual orientation, and desire as ways of being human (though they surely must do this), but also to those interpersonal processes that allow bodies to emerge as such, and the role philosophy plays in exploring particular types of human lives-those that follow the line, so to speak-over others that do not.

\section{Reading Ahmed, Thinking Disability}

At this point, we should ask: what might Queer Phenomenology have said if it did talk about disability? Let me provide three potential avenues. First, and here I am taking cues from "The Orient and Other Others", Ahmed might emphasize how disability is an outcome of a material, interpersonal and symbolic order, much like how race is the outcome of racialization. We might say, following de Beauvoir's famous trope, that bodies become what they are, be they raced, abled or gendered in the midst of one another. Disability emerges in and through disablement. There are many ingredients in this recipe. Some of them are somatic, but many are not. There is a cultural milieu in which bodies gain the disability label, and materials and material environments that bring forth or exclude bodies in public life. The bodily "I-can" does not fall from the sky. Ability is made, put to work in the life-world, granted to some and not others. It is made up in the same phenomenal space she explores throughout the book, in our orientation towards things, others, and in orienting ourselves to a shared past and future.

Secondly, if attuned to the politics of disablement, Ahmed's book could certainly highlight the role that professional practices play in the production of disability as a mode of personhood. Whereas she develops an historical critique of Freudian psychoanalysis' troubled relationship with the lesbian woman in "Sexual Orientation", we might look to rehabilitation as the dominant scientia inhabiles, the technical apparatus that manages and defines disability. ${ }^{1}$ Here we are quite close to the work of Ahmed's poststructuralist teachers, Foucault especially. But there is more going on than the historical angle to subject formation-Ahmed might attend to the problem of the lived body, outside of historical ontology to the human experience of the here-and-now medical encounter.

1 Nicholls employs Foucault's archeological method to demonstrate the active discursive and practical elimination of 'the erotic' in the historical transition from massage to physical therapy. 
We return again to the institutional spaces where the I-can or ability-to is experienced and made possible. In clinical space, disability is not simply a particular way of "bodying-forth" into the world. ${ }^{2}$ When disability emerges as a way of human being, it does so carrying a great deal of medical baggage. It does so both through lay explanations of the body-gone-wrong propped up with reference to the medical dispositif, coupling a truth regime and associated set of practices, and the problem-solution trajectory demanded by that coupling in the clinical space. ${ }^{3}$ This form of life is not without its own modes of orientation, available to personally-informed phenomenological scrutiny. ${ }^{4}$

Finally, for this threefold list at least, Ahmed could very easily explore the kinds of bodily orientations to which desire is made available in, to invoke Foucault, "societies such as ours" (Foucault, History). In her discussion of lesbian affect, she questions what sorts of orientationstowards-bodies are seen as legitimate modes of desire, and what kinds of orientations deviate from that line. There is a burgeoning literature within disability studies exploring this very same topic, asking who is a candidate for desiring subjectivity in the first place, or bluntly, who gets to be sexual at all (McRuer; Shakespeare, "Sexual Politics"; Shakespeare, "Disabled Sexuality"). Following Robert McRuer's lead, the point is not solely that heterosexuality is the dominant modality of desire (this is, of course, the case), rather, it is a smaller instance of a greater cultural politics where certain (white, able, straight, male) bodies count and others are accounted for against this rubric. The site of critique expands from heterosexual subjectivity as the benchmark of human existence to the legitimate participation in these sorts of relations at all-acceptable forms of human desire and human being more generally.

While each of these possible lines of thought draws from different components of Ahmed's argument, they, like the three main chapters of Queer Phenomenology, intersect in the politics of subject formation. In the successive chapters of that book, there is a clear movement from an

${ }^{2}$ I take the quoted phrase from Heidegger's Zollikon Seminars. For an extended discussion of the importance of these seminars, and Heidegger's prior philosophical neglect of the body, see Aho (Heidegger's Neglect) and Askay.

${ }^{3}$ Here I am referring to the summary of that philosophers' thought, as presented in his Birth of Biopolitics lectures: "The point of all these investigations concerning madness, disease, delinquency, sexuality, and what I am talking about now, is to show how the coupling of a set of practices and a regime of truth form an apparatus (dispositif) of knowledge-power that effectively marks out in reality that which does not exist and legitimately submits it to the division between true and false." (19)

${ }^{4}$ I describe my own experience in Abrams ("Flawed by Dasein"). 
individualistic understanding of human existence-as in the first chapter's discussion of Husserl's transcendental subjectivity and Heidegger's Being and Time-to a cultural hermeneutic, where orientations of various sorts are organized in our shared world. ${ }^{5}$ In the case of Husserl's phenomenology, this would be called a move from "subjectivity" to the "intersubjective". 6 I have tried to mimic both endpoints in my extension of her argument to disability and disablement. In each case, from the disablement-disability causality to our exclusionary culture of desire, we are attending not only to individual experiences of disabled personhood, but also taking as our focus the sociomaterial conditions whereby disability becomes manifest, meaningful, and a matter-athand.

In the next section of this paper, I suggest that a similar expanse, extending from the individual to the cultural-institutional, exists within the phenomenological disability studies literature. In highlighting these spaces, I am not arguing that one end is superior to the other. To expand the phenomenological imagination, we need both types of research. We need individual stories of human existence, and we need abstract theoretical work, drawing connections between them. In this spirit, I will present both kinds of phenomenological disability research. This, when compared with the fruits of the earlier sections of this paper, will allow us to chart a phenomenological project that takes embodied differences, racialization and a democratization of desire seriously.

\section{Phenomenological Disability Studies, Individual and Institutional}

Here I will select two bibliographic entries for each of the "individual" and "institutional" phenomenologies of disability, with the caveat that such a typology is merely a heuristic scale, rather than a hard and fast distinction. In the "individual" camp I look to Toombs' "The Lived Experience of Disability" and the pioneering "Disability Studies and Phenomenology" (Paterson and Hughes). Like Ahmed's book, both pieces are autobiographical explorations of disabled personhood using phenomenology as a guide. The two institutional pieces I examine are Titchkosky and Michalko's "The Body as a Problem of Individuality" and Aho's "Medicalizing Mental Health: A Phenomenological Alternative". While the former is located squarely within the disability

${ }^{5}$ I think this shift in emphasis is still the case, even as Ahmed introduces her personal experiences of orientation toward the end of her book. Even autobiographically, she is self-reflective, I think, in light of collective understandings of race, specialization and temporality. She uses a self, herself, as an entry point into the greater whole.

${ }^{6}$ Heidegger would not, as I shall explain below. 
studies literature, Aho's paper is more of an outlier, while still attending to embodied differences. I include it to show how phenomenological methods allow disability studies to extend their purview past merely physical conditions (Shakespeare, Disability Rights) and addresses the governance of disability as a technical problem in need of a solution by biologically-oriented psychiatry, as considered in the previous section. Together, reading these papers will let us extend Ahmed's argument to new territory, while maintaining Queer Phenomenology's critical outlook.

S. K. Toombs' "Lived Experience of Disability" explores her life with chronic, progressive multiple sclerosis. While Ahmed draws from a plurality of thinkers in Queer Phenomenology, Toombs restricts herself to Merleau-Ponty and a small supporting cast (Sartre, and, to a lesser extent, Schütz, and Husserl). The exploration of the lived body in the Phenomenology of Perception is Toombs' principal tool. She begins by contrasting the disabled object body-as-object with her lived experience of disability. "I do not experience the lesion(s) in my brain. . . Rather, my illness is the impossibility of taking a walk around the block or of carrying a cup of coffee from the kitchen to the den" (10). Disability, as it is lived, is first and foremost a way of being, rather than an objectively present lack in an observed body. Using the example of travel to a conference, Toombs demonstrates how the lived and object bodies coalesce in the everydayness of life with multiple sclerosis. This involves not only exploring the world from a disabled body, but also encountering that body as a circumspect object (as in moments of breakdown) and in frequently "casing" new environments to see their adaptability.

Of particular interest to me, as a sociologist living with another progressive condition ("Becker muscular dystrophy", says the MDs), is Toombs' reformulation of the phenomenological "I can". An "I-can"/"I-cannot" binary cannot, she argues, encapsulate the fluidity found in the lived experience of progressive illness. The "I-can-and-will-continue-to" is a learned, partial, and temporary achievement, based in both embodiments and surroundings, against which all bodily tasks must be judged. Living with progressive illness requires a constantly changing tool-set: with changes to bodies and environments come new skills that must be learned to make routines possible. Activities are permitted only so long that legs hold out and muscles maintain strength, until new tactics and environmental aids can be discovered and learned. The bookcase in Toombs' hallway, for example, was once simply a place for papers, it became a ledge to grasp en route to the washroom, and, then, a barrier for her wheelchair. These modes of tacit expertise are far more fickle than some of 
the philosophical literature on the subject presumes (Polanyi): upstream structures of ability must be taken into consideration for a fuller account of that concept. Here little to no work is required to bridge Ahmed and Toombs' arguments. Both point to the social and material structures through which the "I can" is put to work, or, and far too often, just out of reach.

Paterson and Hughes' "Disability Studies and Phenomenology" is a theoretical meditation on disability politics, using one of the authors' personal experience of speech impairment as a means to ground their abstract thinking. The paper builds on their highly cited phenomenological critique of materialist models of disablement (Hughes and Paterson), arguing that a strict materialism fails to sufficiently account for lived, disabled body. Their carnal politics of everyday life are based in the same embodied phenomenology found in Toombs, with the notable addition of Leder's The Absent Body. Paterson and Hughes take Leder's phenomenology of bodily dys-appearance-the way the body is brought forth as object in moments of dysfunction-and apply it to instances of social dysappearance, when individuals are forced to see their own impairments and otherness in moments of collective breakdown. Here the story of speech impairment has more to do with an affront to real-time communication, as an interpersonal convention, than embodied capacity.

When one is confronted by social and physical inaccessibility one is simultaneously confronted by oneself; the external and the internal collide in a moment of simultaneous recognition. When one encounters prejudice in behaviour or attitude, one's impaired body 'dys-appears'. The body of a person with a speech impairment 'dysappears' when faced with (socially produced) embodied norms of communication. Exclusion from and disruption to communication is not therefore a matter of the ability of an impaired person to communicate, but about conventions and norms of communication, which are (a priori) hostile to non-conforming forms of physicality. [...] The impaired body 'dys-appears' as a consequence of the profound oppressions of everyday life (603).

This argument shares a great deal with the work explored above. Like Toombs, Hughes and Paterson show how bodies emerge as disabled in the everyday lifeworld. Disability is not simply a pre-shaped, asocial entity built into impaired bodies. It emerges in and through sociomaterial 


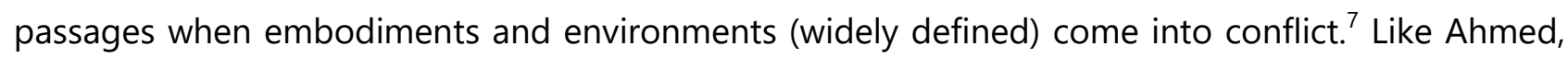
they emphasize orientation, in that disability emerges in moments of disorientation when bodies are made to appear as different because they do not 'follow the line'. Further, Paterson and Hughes, like each of those cited before them, give support for the argument I have tried to establish throughout this paper, namely that disabled (or desiring, or racialized) subjectivity is not, in itself, primordial. It is established, recognized and accorded in the to-and-fro of daily life, in our materially situated and institutionally organized coexistence within the lifeworld, the stuff of the interaction order (Goffman, "Interaction Order").

In comparison to the individually-oriented work of Toombs, Paterson and Hughes, Aho, Titchkosky and Michalko present a relatively more abstract discussion of disabled personhood, as it is put to work in larger scale institutional structures, in the pharmacological-psychiatric and university accessibility apparatuses, respectively. To repeat: in moving to the institutional scale I do not mean to suggest that this higher level of abstraction is more important. Rather, I want to emphasize that phenomenological work in disability studies, like Queer Phenomenology, takes place at numerous registers, each involving the production of personhood. Any phenomenological account of the politics of personhood must take both ends of this spectrum seriously.

Tanya Titchkosky and Rod Michalko's "The Body as a Problem of Individuality" applies Edmund Husserl's and Alfred Schütz's twin phenomenologies of the lifeworld to accessibility discourse in the university setting. They begin by outlining Husserl's account of the lifeworld in his Crisis (121), the "pregiven world in which science and every other life-praxis is engaged", tempered with Schütz's common stock of knowledge, the "natural attitude", attained to navigate the life-world as a shared cultural space (Schütz and Luckmann 3).

It is, then, this taken-for-granted life-world and the natural attitude that represents, for us, the genesis of disability frameworks. . . Disability is a frame that can, upon analysis, teach us much about the life-world that generates it. But herein lies an irony-disability is framed as a phenomenon located and locatable only outside of the taken-for-granted life-world as well as outside the natural

\footnotetext{
${ }^{7}$ I borrow this language of 'passages' from Moser and Law.
} 
attitude. Disability is thus understood as marginal to the common-sense world and, as such, outside intuitively given reality (Titchkosky and Michalko 132).

While the lifeworld provides us a window into the sensuous and institutional apprehension of disability, it presents an account of why disability is engaged as a problem, because it challenges the natural order of things in our aggressively individualistic, market-oriented culture-and especially so in the case of the higher education sector (Titchkosky). When Accessibility Services, the name used at the University of Toronto, provides a solution to the problem of disability, it reinforces its problematic status, and recreates those institutional circumstances where business as usual education might continue. The chapter is, in sum, a cultural phenomenology of the life-world tempered by critical disability politics.

Aho's "Medicalizing Mental Health" is a cultural phenomenology of mental illness, and its overwhelming medication. Here I would apply the addendum "discourse" to "mental illness", but I feel that may discount the frequent emphasis on material practices, maintained throughout Aho's paper. Again, Foucault's dispositif is apt. Aho begins by exploring the political economy of psychiatry in the United States, using the relationships between that industry and the American Psychiatric Association's Diagnostic and Statistical Manual of Mental Disorders (hereafter DSM; then in volume four, now five) as exemplary of "medicalized mental helath". Aho argues that the hermeneutic phenomenology of Martin Heidegger and Hans-Georg Gadamer provides a viable alternative to the mode of personhood, or patienthood, presumed by the biomedical diagnostic categories presented in the later versions of the DSM. ${ }^{8}$ Aho draws from a line of argument begun by Thomas Szasz regarding the scientific validity of psychiatric categories. ${ }^{9}$ Unlike other modes of medical inspection (pathology, for Szasz), psychiatry cannot rely on strictly organic understandings

${ }^{8}$ lan Hacking's Rewriting the Soul is a fascinating examination of the transition from the DSM-III to the DSM-IV, and the emergence of dissociative identity disorder (née multiple personality disorder). Of interest to us here is the elimination of many of the Freudian undertones of the DSM-III in the formulation of the biomedical model of mental pathology.

${ }^{9}$ Though Szasz stated this critique first, Aho cannot be said to object to the biomedical formulation of mental illness in the same way. Szasz argues that mental illness is not a disease because psychiatry cannot derive its diagnoses from organic states, as in the emblematic case of lesions. Mental illness is a myth because behavior problems are categorically different than organic ones: they cannot be diseases at all. The implied methodological dualism, between mental behaviour and physical organ-states, would not convince Aho because of his Heideggerian heritage, which opposes not the distinction between mental and physical substance, but the ontology of substance more generally. For an exploration of substance dualism, substance ontology, and the phenomenology of disability, see my "Cartesian Dualism". 
of illness. Rather, it appeals to behavior (Goffman, "Mental Symptoms"). Phenomenology allows us to pursue a human science of mental illness, instead of one that elects for medication before all else. $^{10}$

Hermeneutic phenomenology is uniquely suited to challenge core assumptions in psychiatry by expanding the narrow conception of the self as an enclosed, biological individual and recognizing the ways in which our experience of things-including mental illness-is shaped by the socio-historical situation into which we grow. Psychiatry's first priority, in this regard, is not to identify an observable pathology that fits neatly into the ready-made diagnostic categories of the DSM but rather to suspend the prejudices that come with being a scientist or medical doctor in order to hear the patient describing her/his own experience (Aho, "Mental Health" 243-245).

Phenomenology, as an ontological exploration of what we are as human beings-in-the-world, allows us to escape the empiricist prejudices of biomedically-informed psychiatry. However, Aho argues, Husserlian phenomenology is not up to this task because it takes the structures of consciousness, embodied or not, as the basis in which we primarily engage the world (both at face value, and as abstracted to the level of "transcendental subjectivity"). This passes over our basic mode of being-in-the-world, what Heidegger calls Dasein. In the tacit meaning-structures disclosed in everyday life, explored in Being and Time under the name "care", lies the opportunity to explore the modes of personhood found in depression, schizophrenia, and the like, as ways of being-inthe-world, rather than a pseudo-organic problem solely in need of a pharmacological fix. ${ }^{11}$ Here, we are looking for genuine dialogue between practitioner and patient, to Heidegger the mutual disclosiveness of Being to the shared world through language, rather than a quick, one-sided diagnosis and prescription.

These two institutional approaches have their differences. Foremost is a philosophical contrast. Titchkosky and Michalko use Husserlian phenomenology to make sense of disability, whereas Aho

${ }^{10}$ I write "before all else" because, as with Aho, I do not want to discount many of the benefits that have come with new drugs. With this stated, I also agree with his argument that medication should be seen as one of many viable treatments for mental illnesses.

${ }^{11}$ For an extensive account of schizophrenia as a distinct, but no less human, mode of being-in-the-world, see Louis Sass' excellent paper, "Heidegger, Schizophrenia, and the Ontological Difference" (Sass). 
employs a Heideggerian, existential perspective. Husserl, as is well known, uses the phenomenology of the life-world as a launching point through which to engage transcendental subjectivity, to examine the structures of conscious experience in themselves. The emphasis is epistemological. Heidegger (the early, Being and Time Heidegger), by contrast, examines thoughtless practical action to uncover our fundamental way of being-in-the-world, exploring the grounding disclosure of Being. This work is ontological. Instead of drawing a sharp distinction between these two phenomenological projects, I want to emphasize their similarities. While both move away from everydayness (knowing and dwelling alike) to do different kinds of philosophical work, they begin in the same space: practical human life. It is this space where we need to take account of the wide variety of human existence in order to do more democratic phenomenology, of all sorts.

These similarities extend to the individual camp as well. While Toombs and Paterson and Hughes draw on personal experiences to make sense of abstract phenomenology, Aho, Titchkosky and Michalko engage impairment at the cultural register, exploring how institutions make sense of embodied differences at the larger scale. As I have repeated throughout this paper, we must pursue both types of projects if we are to democratize the phenomenological project in any meaningful way. We need large-scale sketches of the institutionally organized spaces where we find ourselves, and first-hand accounts of what it means to organize our lives therein. ${ }^{12}$

We should review the progress made to this point, before moving on. I began this paper with a reading of Ahmed's Queer Phenomenology, outlining how she queers our orientation to things, to those we desire, to cultures and peoples made Other. Ahmed's work did not address disability directly. It was not difficult, however, to extend these existing arguments to disability as manifest in everyday life. Next, I examined some phenomenological work exploring disability at both the institutional and individual levels. In each case, Queer Phenomenology and those phenomenological disability studies did a lot of the same things. At risk of oversimplification, each author suggested that modes of personhood-race, disability, whatever-are emergent products of worldly interaction, made and unmade in our institutionally organized, materially equipped coexistence. Not all of these orientations are optimal for persons who must negotiate them, but nonetheless

12 This argument is hardly novel; here I take a great deal of inspiration from lan Hacking's ("Foucault and Goffman") reading of Goffman and Foucault together. He explores existentialist philosophy in that paper as well, further precedent for the argument here. 
they are all made in the shared lifeworld. In the final section of this paper, I want to mimic another move made in Queer Phenomenology, a return to the basis of phenomenology as a method of inquiry. Ahmed does not simply apply phenomenology to the lives of queer people. She queers the project itself. In this same line of thought: if we have added other modes of humanity to the mix, what does this say about the phenomenological project writ large? What can the classic texts learn from our journey?

\section{Returning to the Basis of the Phenomenological Project Itself}

In bits and pieces scattered throughout this paper, I have argued that subjectivity, as a description of personhood, is made and unmade in the common world, in the interaction order. At first glance, this seems antithetical to the phenomenological project, which explores the conditions of human being (conscious, practical or otherwise). Are we at an impasse? To end the paper without resolving this question would hardly be fair. In this final section, then, I aim to tie up these loose ends. In doing so, I want to show how a phenomenology that takes disability, race, and desire seriously contrasts with the classic work of Husserl and Heidegger, which has been employed throughout this paper. I cannot, of course, explore the entirety of either philosopher's work. I will restrict myself to a single book each, Husserl's Crisis and Heidegger's Being and Time, and to the role that subjectivity plays in those texts.

Husserl's Crisis takes as its object the hubris endemic to the modern, positivist worldview. We are in crisis because we have forgotten that nature only gained its factual self-evidence through human measurement (What Husserl historically traces from Galileo as the "mathematization of nature"; 23). It is only in the life-world, and our natural attitude therein, where these measurements occur and are put to work. We can recover what is particularly human about our experience of this world by "bracketing" that natural attitude-this is the famous phenomenological epoché-and turning thought unto itself. In doing so, we are able to explore the structures of consciousness that have been ignored by rationalist (Descartes) and empiricist philosophers (Hume) alike. Here we move to the realm of "transcendental subjectivity", where we engage ourselves purely as ego and others as alter egos, to transcendental subjectivity and intersubjectivity respectively. A truly scientific, philosophically based psychology—and this is Husserl's goal-must recognize these structures, and eschew the naïve psychologism pervading the positivist mindset. 
In Being and Time, written before Husserl's Crisis, yet very much a reaction to its philosophical heritage, Heidegger locates the concept of subjectivity in the history of western philosophy, one that has forgotten the basic question of Being. Subjectivity, as a conceptual approach to human existence, is part and parcel to the "ontology of objective presence", reducing the things of the outside world as extended substance, and treats the human mind as a place that represents these impressions via mental substance. ${ }^{13}$ Heidegger's fundamental objection is not that mental and extended substance should be unified, but that the concept of substance passes over our basic way of dwelling in the world. It emphasizes a theoretical way of looking at the world, rather than our tacit and meaningful navigation of it in practical life, what Heidegger calls care (the famous example, used in Queer Phenomenology, is the carpenter's use of equipment). Subjectivity is an ontic description of the world, exploring objects and their properties theoretically, and passes over fundamental ontological questions pertaining to our own finitude and existential status (the distinction is what Heidegger calls the "ontological difference"; Being and Time 211n). Because subjectivity ignores these questions, it is a bad description of human existence.

The arguments found in these two classical texts appear, at first glance, positively alien to the phenomenological work explored earlier in this paper. I disagree; though they may talk past one another, the territory that they chart is the same: the contours of meaningful human life. As one who uses phenomenology to make sense of my own personal existence (existence as a disabled person, at that) I believe it is necessary —I know it is necessary - to expand the kinds of human lives that we take as representative of human life, within philosophical frameworks and without. As in Queer Phenomenology, this means much more than simply applying phenomenological philosophy to new spaces and leaving it at that. It means amending that core project to better reflect the plurality of human lives from the outset. The question, then, is this: how might Husserl's and Heidegger's work be modified to do so?

In Husserl's movement to transcendental subjectivity, and thus to intersubjectivity, he either assumes that all of the conditions necessary to bring us in contact with our fellow humans are also transcendent, or he ignores them. As almost all of the work covered to this point has made clear, this is not and cannot be the case. There are very important material and social conditions-

${ }^{13}$ This is what Ryle (Concept) would call the "doctrine of the ghost in the machine." His extremely cautious but thorough review of Being and Time (Ryle, "Review") demonstrates his deep familiarity with Heidegger's most famous book. 
immanent conditions - that must be met in order for human lives to flourish, and for human lives to flourish together. In order for the transcendental orientation to take place at all, a great deal of infrastructure must be in place. This is so in the first chapter of Queer Phenomenology, in Toombs' daily life with multiple sclerosis, and in the institutionalized university setting explored by Titchkosky and Michalko. Even if it is granted that we all possess, as human beings, the existential equipment to be transcendental subjects as described in Husserl's Crisis (and I regard this presumption with cautious suspicion), to have that potential realized and recognized is a different sort of achievement entirely. While charting the boundaries of human conscious existence, we cannot forget the immanent social and material infrastructure that makes such inquiry possible.

Just as Heidegger rejects subjectivity as an adequate description of human existence in Being and Time, he would undoubtedly reject disability studies and queer theory as needless humanisms that also pass over the basic questions of human existence. "Humanism," as he writes in his famous and characteristically androcentric "Letter" on the subject, "is opposed because it does not set the humanitas of man high enough." This continues:

Of course the existential worth of man does not consist in his being the substance of beings, as the "Subject" among them, so that as the tyrant of Being he may deign to release the beingness of beings into an all too loudly bruited "objectivity" ("Letter" 233-234).

Not only would Heidegger suggest that the type of work we are doing here is ontic, enframing human being as a subject and failing to account for the ontological difference, he would surely regard the political expediency I have emphasized as a foray into what is now called "identity politics," with similar dismissal. Perhaps. To this charge I have two responses. One is philosophical. The second is personal. The philosophical objection is this: we need only reject subjectivity as a register of human existence when we try to use it in place of our meaningful existence, our Dasein. No, subjectivity (so defined by Heidegger) cannot encapsulate our constant being-towards-death, or the tacit structures of relevance that we rely on to carry out our worldly tasks. But this need not be so for subjectivity to be real, albeit a measure divorced from the ontological conditions of our existence. When we describe someone's opinion as "subjective" in lay dialogue, or when we read Descartes' Meditations, these terms have meaning for us. Its meaning is enacted in the common 
world (not the Being of Dasein). In this, revised sense, subjectivity is a measure of human existence, just one that is made and shaped in the shared world.

My personal response is less charitable to Heidegger. His personal life is not to be emulated. As his "Black Notebooks" (named for their covers) continue to be published in German and translated into English, we are becoming more and more aware about the political extremes to where his thought was pressed (little wonder why he famously rejected biographic details of philosophers past). Phenomenology, if the content of the notebooks still can be called that, has a deeply political potential, to put it lightly. If I must choose a path, I will choose Ahmed's. In taking a phenomenological perspective on her own existence, she offers us the potential not only to describe the many ways in which human lives can be shaped or neglected, but also an opportunity to shape them for the better. If Heidegger's philosophy gives us some insight into this greater journey, then so be it. If not: so be it.

\section{Works Cited}

Abrams, Thomas. "Cartesian Dualism and Disabled Phenomenology." Scandinavian Journal of Disability Research (2015), Forthcoming.

---. "Flawed by Dasein? Phenomenology, Ethnomethodology, and the Personal Experience of Physiotherapy." Human Studies 37 (2014): 431-446. Print.

Ahmed, Sara. Queer Phenomenology: Orientations, Objects, Others. Durham: Duke University Press, 2006. Print.

Aho, Kevin A. Heidegger's Neglect of the Body. Albany: State University of New York Press, 2009. Print.

---. "Medicalizing Mental Health: A Phenomenological Alternative." Journal of Medical Humanities 29 (2008): 243-59. Web.

Askay, Richard R. "Heidegger, the Body, and the French Philosophers." Continental Philosophy Review 32 (1999): 29-35. Print.

Foucault, Michel. The Birth of Biopolitics: Lectures at the Collège de France 1978-79. Trans. Graham Burchell. New York: Palgrave Macmillan, 2008. Print.

---. The History of Sexuality Volume 1: An Introduction. Trans. Robert Hurley. New York: Random House, 1978. Print.

Goffman, Erving. "Mental Symptoms and Public Order." Interaction Ritual: Essays on Face-to-Face Behaviour. New York: Pantheon, 1967. 137-148. Print.

---. "The Interaction Order: American Sociological Association, 1982 Presidential Address." American Sociological Review 48 (1983): 1-17. Print. 
Hacking, lan. "Between Michel Foucault and Erving Goffman: Between Discourse in the Abstract and Face-to-Face Interaction." Economy and Society 33 (2004): 277-302. Print.

---. Rewriting the Soul: Multiple Personality and the Science of Memory. Princeton: Princeton University Press, 1995. Print.

Heidegger, Martin. Being and Time. Trans. Joan Stambaugh. New York: State University of New York Press, 1996. Print.

---. "Letter on Humanism." Martin Heidegger: Basic Writings. 2nd ed. Ed. David Farrel Krell. San Francisco: Harper Collins, 1993. 213-266. Print.

---. Zollikon Seminars. Trans. Franz Mayr and Richard Askay. Evanston: Northwestern University Press, 2001. Print.

Hughes, Bill, and Kevin Paterson. "The Social Model of Disability and the Disappearing Body: Towards a Sociology of Impairment." Disability \& Society 12 (1997): 325-340. Print.

Husserl, Edmund. Ideas: General Introduction to Pure Phenomenology. Trans. W. R. Boyce Gibson. New York: George Allen \& Unwin, 1931. Print.

---. The Crisis of European Sciences and Transcendental Phenomenology; an Introduction to Phenomenological Philosophy. Trans. David Carr. Evanston: Northwestern University Press, 1970. Print.

Leder, Drew. The Absent Body. Chicago: University of Chicago Press, 1990. Print.

Marx, Karl. Capital: A Critique of Political Economy, Volume One. Trans. Ben Fowkes. London: Penguin Books, 1990. Print.

McRuer, Robert. Crip Theory: Cultural Signs of Queerness and Disability. New York: New York University Press, 2006. Print.

Merleau-Ponty, Maurice. Phenomenology of Perception. Trans. Colin Smith. New York: Routledge, 1962. Print.

Moser, Ingunn, and John Law. "Good Passages, Bad Passages." Actor-Network Theory and After. Ed. John Law and John Hassard. Oxford: Blackwell, 1999. 196-219. Print.

Nicholls, David A. "Foucault and Physiotherapy." Physiotherapy Theory and Practice 28 (2012): 447453. Print.

Paterson, Kevin, and Bill Hughes. "Disability Studies and Phenomenology: The Carnal Politics of Everyday Life." Disability \& Society 14 (1999): 597-610. Print.

Polanyi, Michael. The Tacit Dimension. Garden City: Doubleday, 1966. Print.

Ryle, Gilbert. "Review of Sein Und Zeit." Mind 38 (1929): 355-370. Print.

---. The Concept of Mind. Chicago: University of Chicago Press, 1949. Print.

Sass, Louis. "Heidegger, Schizophrenia and the Ontological Difference." Philosophical Psychology 5 (1992): 109-132. Print.

Schütz, Alfred. Collected Papers I. The Problem of Social Reality. Ed. H. L. van Breda and M. A. Natanson. The Hague: Springer, 1974. Print.

Schütz, Alfred, and Thomas Luckmann. The Structures of the Life-World. Trans. Richard M. Zaner and Tristram Jr Engelhardt. Evanston: Northwestern University Press, 1973. Print.

Shakespeare, Tom. Disability Rights and Wrongs. London: Routledge, 2006. Print. 
---. "Disabled Sexuality: Towards Rights and Recognition." Sexuality and Disability 18 (2000): 159166. Print.

---. "The Sexual Politics of Disabled Masculinity." Sexuality and Disability 17 (1999): 53-64. Print.

Szasz, Thomas. The Myth of Mental Illness. Revised. New York: Harper Perennial, 2010. Print.

Titchkosky, Tanya. The Question of Access: Disability, Space, Meaning. Toronto: University of Toronto Press, 2011. Print.

Titchkosky, Tanya, and Rod Michalko. "The Body as The Problem of Individuality: A Phenomenological Disability Studies Approach." Disability and Social Theory: New Directions and Developments. Ed. Dan Goodley, Bill Hughes, and Lennard Davis. Houndmills, Basingstoke, Hampshire: Palgrave Macmillan, 2012. 127-142. Print.

Toombs, S. Kay. "The Lived Experience of Disability." Human Studies 18 (1995): 9-23. Print. 